\title{
Newer Fluorometric Methods for the Analysis of Biologically Important Compounds
}

\author{
G. G. Guilbault \\ Department of Chemistry, Louisiana State University, New Orleans, La. 70122
}

(June 15, 1972)

\begin{abstract}
Newer fluorometric methods for the analysis of biologically important compounds will be discussed: enzymes such as LDH, alkaline phosphatase, lipase and cholinesterase, and substrates such as glucose, urea and uric acid. These methods are based on the production of fluorescence initiated by an enzymic reaction.

New reagentless fluorescence methods will be described for enzymes and substrates. These methods are highly precise $(1 \%)$, fast (less than 1 minute) and involve no preparation of reagents. These methods, as adapted to clinical laboratory procedures, will be discussed.
\end{abstract}

Key words: Enzymes, fluorometric analysis; fluorometry of enzymes; fluorometry of substrates; silicone pad; solid surface fluorometry.

\section{General}

Enzymes are biological catalysts which enable the many complex chemical reactions, necessary to the existence of life, to take place at ordinary temperatures. Because enzymes work in complex living systems, one of their outstanding properties is specificity. Thus, an enzyme is capable of catalyzing a particular reaction of a particular "substrate" to produce a characteristic and measurable reaction end product. This specificity of enzymes and their ability to catalyze reactions of substrates at extremely low concentrations is of significant use in biochemical analyses.

Enzyme catalyzed reactions have long been used for such analytical purposes for determining the presence of specific substrates, enzyme activators, enzyme inhibitors, and enzymes themselves, and in determining the concentration of these substances. Numerous methods have been described for the determination of enzymic activity between an enzyme and a substrate. Until recently, however, the disadvantages associated with the use of enzymes in these analytical techniques have seriously limited their usefulness.

A detailed discussion of the use of enzymes for analysis can be found in review articles by Guilbault [1-3] and books by Guilbault [4] and Bergmeyer [5].

The concentration of substrate participating in an enzyme reaction can be calculated in one of two general ways. The first method measures, by chemical, physical, or enzymatic analysis, either the total change that occurs in the end product or the unreacted starting material. In this method, large amounts of enzyme and small amounts of substrate are used to insure a com- plete reaction. In the second method, which is a kinetic method, the initial rate of reaction is measured, in one of many conventional ways, by following the production of product or the disappearance of the substrate. In this method, the rate of reaction is a function of the concentration of substrate, enzyme, inhibitor and activator.

On the other hand, because enzymes are catalysts, and as such affect the rate and not the equilibrium of reactions, their concentration and activity must be measured by the rate or kinetic method. Similarly, activators and inhibitors that affect the enzyme's catalytic effect can be measured only by the rate method. While, as pointed out above, the substrate can be measured either by a total change or a rate method, the latter method is faster because the initial reaction can be measured without waiting for equilibrium to be established. The accuracy and precision of both methods are comparable.

In the past, manometric methods, $\mathrm{pH}$ procedures, and spectrophotometry have been used for determining enzyme activity. Spectrophotometry has been generally preferred because of its simplicity, its rapidity and the capability of measuring lower enzyme and substrate concentrations. Spectrophotometry embraces the use of colorimetric methods where colored products are produced as a result of enzyme activity, and fluorescent methods where fluorescent compounds are produced as a result of enzyme activity. Fluorescent procedures are several orders of magnitude more sensitive than colorimetric methods and thus have replaced the colorimetric methods in numerous instances.

Previous fluorometric methods, although they have 
been improvements over other prior art methods of determining enzyme activity have not eliminated all of the problems associated with enzymic analyses. Fluorometric analysis depends on the production of a fluorescent compound as a result of enzyme activity between a substrate and enzyme. The rate of production of the fluorescent compound is related to both the enzyme concentration and substrate concentration. This rate can be quantitatively measured by exciting the fluorescent compound as it is produced and by recording the quantity of fluorescence emitted per unit of time with a fluorometer.

The prior methods for fluorometrically measuring enzyme reaction rates, however, have been wet chemical methods and rely on reacting a substrate solution with an enzyme solution. Wet chemical methods in- volve time-consuming and wasteful preparation of costly substrate solutions and enzyme solutions. For example, when determining the presence and concentration of an enzyme, a substantial amount of substrate must be accurately weighed and dissolved in a large amount of buffer solution usually about $100 \mathrm{ml}$ to prepare a stock solution. The enzyme reaction is then usually carried out by measuring, for example, $3 \mathrm{ml}$ of stock substrate solution into an optical cuvet, adding a measured amount of the enzyme solution to the substrate solution, and recording the change in fluorescence eminating from the resultant solution per minute with a fluorometer. This standard wet chemical method is costly and wasteful because laboratory trained technicians' time and relatively large quantities of expensive substrate are required.

\section{Solid Surface Fluorescence Monitoring System}

Solid-surface fluorometric methods, using a reagentless system, have been developed for the assay of clinically important enzymes, substrates, activators and inhibitors. The method comprises forming a solid reactant film of one of the reactants on an inert silicone matrix pad, contacting the film of the first reactant with a solution of the second reactant (substance to the measured) to produce a fluorescent material, and monitoring the change of fluorescence with time to determine the concentration of the second reactant.

The reactant film may be formed by dissolving the reagents in a solvent, depositing the reactant solution on the silicone pad so that the solution spreads evenly over the pad, and evaporating the solvent from solution. The reagent may be applied to the pad either from an acetone solution if a substrate or in a polymeric film such as polyacrylamide if an enzyme. Either substrate or enzyme and/or coenzyme can be deposited on the pad in film form depending upon whether the substance to be assayed is an enzyme or a substrate.

After the pad is formed (fig. 1), it is attached to a slide made of a rigid material, such as a glass or metal slide, by applying an adhesive to the slide and overlying the pad on the adhesive. The pads are placed approximately 1 or $2 \mathrm{~cm}$ from the bottom of the slide (fig. 2).

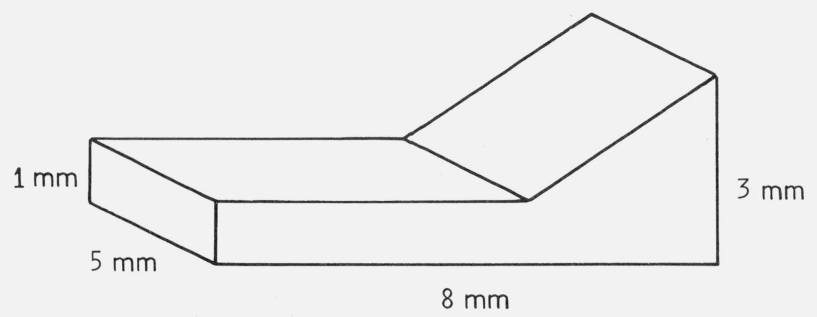

Figure 1. Pad support (all measurements are in $\mathrm{mm}$ ).

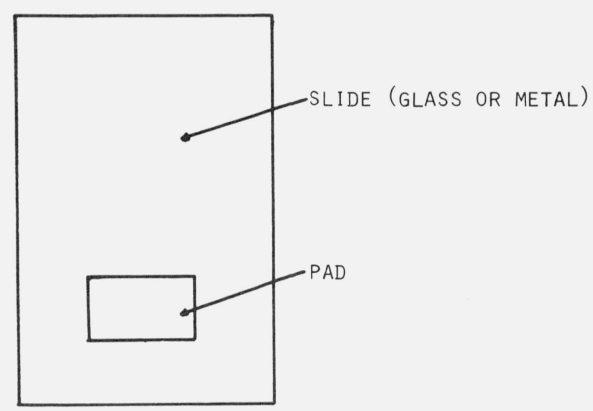

Figure 2. Slide support.

The fluorescent cell consists of a rectangular cell made of ordinary sheet metal, wood or plastic material (fig. 3), having portholes to allow radiation to enter and leave the cell cavity. The top of the cell is provided with guides at opposite sides so that the slide containing the reagents can be reproducibly placed within the cell. In order to obtain as low a background as possible, the cell is painted with a black optical paint having a dull finish.

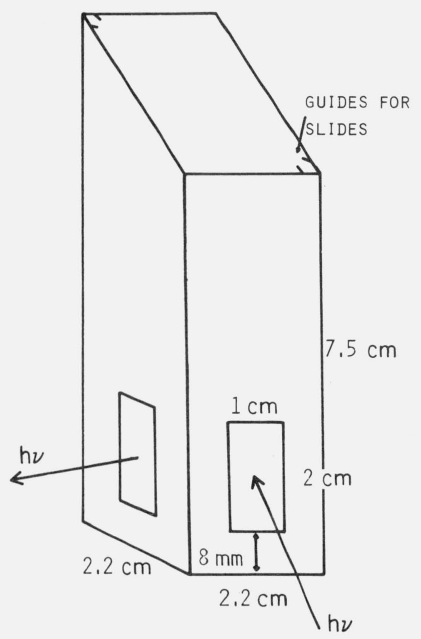

FigURE 3. Fluorescence attachment used to hold pads (all measurements are in $\mathrm{cm}$ ). 
Before the enzyme solution is added, the glass slide is put into the fluorometer and a background reading is taken. A blank rate is taken using all components of the system, except the unknown. The slide is then removed from the fluorometer and $20 \mu \mathrm{l}$ of a solution of the substance to be assayed is applied to the slide. The recorder (100 $\mathrm{mV}$ input) is started immediately, the slide is placed back into the fluorometer, and the rate is recorded. A calibration plot of the change in fluorescence units per minute versus concentration is prepared and used for subsequent analyses of enzyme or substrate.

After a run is completed, the pad can be peeled from the slide, and the slide cleaned and stored for subsequent use.

The physical properties of the silicones and the stability of the reactant films of enzyme and substrate in the presence of silicones further make these materials ideally suited for use. The silicone materials can retain a reactant film on their surfaces for an indefinite time and permit the direct measurement of fluorescence from its surface when an appropriate second reagent solution is dropped onto the first reactant film. Background interference due to light scattering and nonspecific fluorescence are minimal compared to other materials.

The number of enzyme systems that could be monitored by this type of solid-surface device are as numerous as the number of enzyme systems known. Some of the more clinically important systems that will be studied and for which methods have been developed are as follows.

\section{Assay of Clinically Important Enzymes}

\section{A. Cholinesterase}

Low levels of cholinesterase (ChE) are found in individuals with anemia, malnutrition, and pesticide poisoning. High levels indicate a nephrotic syndrome.

Preliminary results have indicated that cholinesterase in solution can be monitored using a film of $N$-methyl indoxyl acetate on the surface of a silicone rubber pad:

\section{$N$-Methyl indoxyl acetate $\stackrel{\mathrm{ChE}}{\longrightarrow} N$-Methyl Indoxyl}

(Fluorescent $-\lambda_{\mathrm{ex}}=4.95 \mathrm{~nm}, \lambda_{\mathrm{em}}=525 \mathrm{~nm}$ )

The rate of production of $N$-methyl indoxyl is followed and is proportional to the cholinesterase concentration. Attempts have been made to develop methods for the direct assay of ChE in blood and body tissue. The reproducibility and accuracy obtainable using several configurations of pad and various experimental conditions have been compared and the optimum system developed. A linear region of $10^{-4}$ to 1 unit has been obtained [6].

Preliminary studies have indicated that pads made from either method were stable for at least 60 days (table 1), if kept in a cold dark place.
TABle 1. Pad stability data ${ }^{a}$

\begin{tabular}{rc} 
Day $^{\text {b }}$ & Rate, \\
\hline 0 & 3.10 \\
2 & 3.04 \\
4 & 3.08 \\
10 & 3.20 \\
30 & 3.00 \\
60 & 3.00
\end{tabular}

a A $500 \mu \mathrm{g} / \mathrm{ml}$ solution of cholinesterase was freshly prepared for each day. Twenty microliters of a $0.1 M$ substrate solution were applied to the pad and allowed to evaporate to dryness.

${ }^{b}$ Days after preparation of pad.

${ }^{c}$ Rates were an average of at least three runs.

\section{B. Alkaline Phosphatase}

High levels of alkaline phosphatase are observed in rickets, Paget's disease, obstructive pandicea, and metastatic carcinoma.

The fluorogenic substrate naphthol-AS-BI-phosphate was used for the assay of alkaline phosphatase in serum. Guilbault et al. [7,8] found that this substrate is the best for the direct assay of alkaline phosphatase in serum. A solution method was used and an accuracy and precision of about 2 percent was obtained. The deep green fluorescent naphthol AS-BI formed is measured. Attempts have been made to monitor this reaction on a solid surface. A drop of serum to be assayed has been added directly to the naphthol AS-BI-phosphate on the surface and the rate monitored. No solutions are required. From $10^{-6}$ to 10 units are assayable [9].

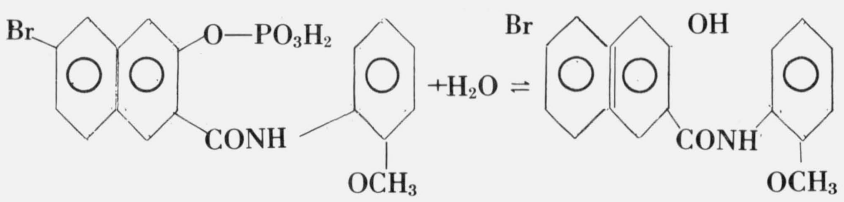

Naphthol AS-BI-Phosphate (Non-Fluorescent)
Naphthol AS-BI

(Fluorescent)
Further attempts have been made to extend the usefulness of this method for a wide variety of biological samples.

The color of the silicone rubber however, affects both the background and reaction rates. With any of the filter systems, the background and reaction rates increase in the order black $<$ grey $<$ clear $<$ white. Each possible combination of pad color and filter was examined and it was found that the most accurate results could be obtained if a combination of 7-54 filter and grey silicone rubber pads were used.

Table 2 shows the results obtained from a series of serum samples. Over 80 serum samples were analyzed with a relative error of \pm 5 percent. 
TABLE 2. Determination of serum alkaline phosphatase

$\begin{array}{cc}\begin{array}{c}\text { Units alkaline } \\ \text { phosphatase } \\ \text { taken }\end{array} & \begin{array}{c}\text { Units alkaline } \\ \text { phosphatase } \\ \text { found }\end{array} \\ & \\ 20 & 21.5 \\ 22 & 19 \\ 24 & 24.5 \\ 26 & 23 \\ 28 & 25 \\ 30 & 31 \\ 31 & 31 \\ 33 & 37 \\ 37 & 34 \\ 39 & 40 \\ 41 & 39 \\ 43 & 42 \\ 48 & 49 \\ 53 & { }^{\mathrm{d}} 54 \\ 61 & { }^{\mathrm{d}} 60 \\ 64 & { }^{\mathrm{d}} 64\end{array}$

a Units expressed as $\mu \mathrm{mol}$ phenolphthalein liberated $\min ^{-1} 1^{-1}$ serum.

b Obtained by multiplying the rate by 31.5 .

c Average from 3 or more different samples-each analysis in duplicate.

d One sample-average of 2 determinations.

Figure 4 shows the correlation between the serum alkaline phosphatase values obtained from the "solid surface" method and alkaline phosphatase values obtained from a solution method employing phenolphthalein phosphate. The graph shows good agreement between the two methods over a wide range of serum values. If the serum values are expressed as $\mu$ mol phenolphthalein liberated $\min ^{-1} 1^{-1}$ serum, then normal serum has 27-105 units.

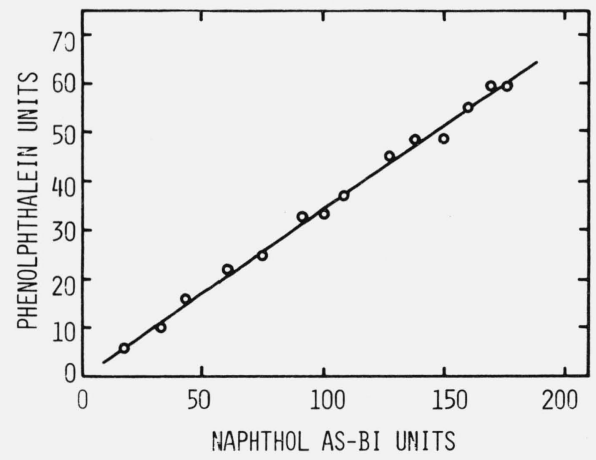

FigURE 4. Correlation between results obtained with naphthol AS-BI method and phenolphthalein method.
Table 3 shows the alkaline phosphatase values obtained from highly jaundiced serum compared to the phenolphthalein phosphate method. All the results from these samples were low and implied a limitation on the method. It is, however, possible to predict which samples will give low results. Generally, it is those samples which are very dark yellow or orangeyellow in color. The light-yellow serum gave good results as did haemolyzed serum. The low values obtained from jaundiced serum is the main limitation of the method, but it is possible to recognize these solutions and carry out the analysis by an alternative method.

TABLE 3. Analytical results obtained from jaundiced serum samples

$\begin{array}{cc}\begin{array}{c}\text { Units alkaline } \\ \text { phosphatase } \\ \text { taken }^{\mathrm{a}}\end{array} & \begin{array}{c}\text { Units alkaline } \\ \text { phosphatase } \\ \text { found }^{\mathrm{a}, \mathrm{b}}\end{array}\end{array}$

$\begin{array}{rr}27 & 18 \\ 34 & 21 \\ 59 & 30 \\ 86 & 21 \\ 135 & 44 \\ 185 & 115 \\ 200 & 138\end{array}$

a Units expressed as $\mu \mathrm{mol}$ phenolphthalein liberated $\min ^{-1} 1^{-1}$ serum.

b Average of 3 results.

\section{Lipase}

A low plasma lipase indicates vitamin A deficiency and some malignancies. Lipase assay is most important in diagnosis of pancreatitis.

Two fluorogenic substrates have been evaluated for the assay of lipase: $N$-methyl indoxyl myristate, a substrate developed by Guilbault and Hieserman [10], and 4-methyl umbelliferone myristate, a substrate recently prepared in our labs.

The production of the green fluorescent naphthol AS-BI or the blue 4-methyl umbelliferone myristate can be followed on the surface.<smiles>Cc1cc(=O)oc2ccccc12</smiles>

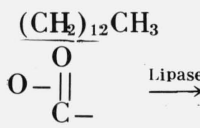<smiles></smiles>

4-Methyl Umbelliferone Myristate $\longrightarrow$

$$
\text { 4-Methyl Umbelliferone } \begin{aligned}
\lambda_{\text {ex }} & =340 \mathrm{~nm} \\
& \lambda_{\mathrm{em}}=450 \mathrm{~nm}
\end{aligned}
$$

A direct assay of lipase $\left(10^{-4}\right.$ to 10 units $)$ in serum and pancreas can be effected. 


\section{Lactate Dehydrogenase}

Levels of this enzyme are elevated in individuals with acute and chronic leukemia in relapse, myocardial infarctions and carcinomatosis.

Fluorometric analysis of dehydrogenases in the past have been based on measurement of NADH fluorescence. Guilbault and Kramer [11] have described a fluorometric method of coupling reduced nicotinamide adenine dinucliotide (NADH) to an electron acceptor (resazurin) in the presence of the cofactor phenazine methosulfate (PMS).

$\begin{array}{ccc}\text { Lactate }+\mathrm{NAD} & \mathrm{LDH} \\ \underset{\begin{array}{c}\mathrm{NADH}+\text { Resazurin } \\ \text { (Non-Fluorescent) }\end{array}}{\mathrm{NADH}}+\mathrm{PMS} & \begin{array}{c}\text { Resorufin }+ \text { NAD } \\ \text { (Fluorescent) }\end{array}\end{array}$

A semisolid state fluorescence method for the analysis of lactic dehydrogenase (LDH) has been developed [12]. The commercially available enzyme in aqueous solution, and the enzyme in blood serum were studied. The serum analysis is compared to a method described by Bergmeyer, et al. [13]. As little as 160 units of $\mathrm{LDH}$ per milliliter of blood serum can be analyzed with an accuracy of better that 3 percent.

The reaction system used was: (I)

$$
\text { Li Lactate + NAD } \underset{\mathrm{LDH}}{\rightleftarrows} \mathrm{NADH}+\text { Pyruvic Acid. }
$$

The rate of production of the fluorescent product NADH was monitored.

Some of the results obtained in the assay of $\mathrm{LDH}$ in serum using the solid surface method are shown in table 4. An average relative error of 2.3 percent was obtained.

\section{Assay of a Clinically Important Substrate}

\section{A. Glucose}

High levels of glucose may indicate diabetes.

Guilbault et al. [14] have described a fluorometric assay system for glucose using glucose oxidase, peroxidase, and $p$-hydroxyphenylacetic acid. The rate of production of fluorescence is proportional to the amount of glucose present.

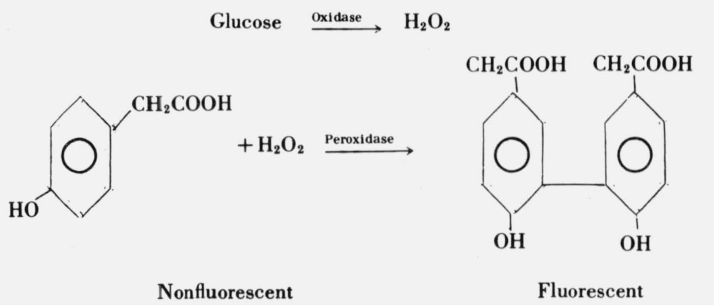

To develop a reagentless surface method for assay of glucose, the enzymes glucose oxidase and per- oxidase, and the substrate $p$-hydroxyphenylacetic acid were placed on the surface. The addition of glucose initiates the reaction; fluorescence is produced and its rate of production will be proportional to the glucose present in blood [15]. A range of $10^{-5}$ to $10^{-1} M$ glucose can be assayed.

TABLE 4. Data and results of the assay of serum LDH using the proposed method

\begin{tabular}{|c|c|c|c|}
\hline Rate, $\Delta F / \min$. & $\begin{array}{c}\text { Concentration } \\
\text { taken }\end{array}$ & $\mathrm{u} / \mathrm{ml}$ Found & $\begin{array}{c}\text { Relative error } \\
\text { (percent) }\end{array}$ \\
\hline 6.6 & 160 & 168 & $\begin{array}{l}+4.9 \\
+4\end{array}$ \\
\hline 7.3 & 190 & 189 & -0.3 \\
\hline 7.2 & 200 & 186 & -6.5 \\
\hline 10.1 & 280 & 276 & -1.3 \\
\hline 13.2 & 360 & 372 & +3.3 \\
\hline 13.9 & 380 & 394 & +3.4 \\
\hline 15.3 & 440 & 437 & -0.6 \\
\hline 16.0 & 460 & 459 & -.2 \\
\hline 17.2 & 500 & 496 & -.8 \\
\hline 18.8 & 560 & 546 & -2.5 \\
\hline 21.4 & 620 & 626 & +1.0 \\
\hline \multicolumn{3}{|c|}{ Average relative error } & 2.3 \\
\hline
\end{tabular}

\section{B. Advantages of Solid Surface Method}

The advantages of this radically new system for the clinical laboratory are:

1. The time required for analysis by present methods is 30 to 60 min to prepare reagents plus 10 to $20 \mathrm{~min}$ per assay. If a sample is available at $1 \mathrm{a} . \mathrm{m}$., the technician must proceed through the regular preparation and analysis routine. The solid surface method requires 10 bottles of pads, one for each of 10 common tests. The technician would open the bottle marked "LDH test," pick out a pad, put it in the instrument on the strip holder, add a $10 \mu \mathrm{l}$ sample of blood or urine, and read out the results directly in $\mathrm{mg}$ percent urea. Total time is about $2 \mathrm{~min}$.

2 . The accuracy of current methods (mostly spectrophotometric) are limited to an error of about 2 to 3 percent over a narrow range (0.15 to 0.85 Abs units). Because fluorescence methods are based on the production of a signal over zero signal, the accuracy of these methods is independent of scale reading, and have an accuracy of 1 percent over a 3 to 4 fold linear range of concentrations.

3 . Temperature must be controlled in all enzyme assays based on a kinetic approach. This is expensive and bothersome. The solid surface fluorescence method proposed is not temperature dependent, since the silicone rubber pad used to support the sample is nonheat conductive. Thus, provided the sample of blood is at the same temperature as used to prepare the calibration plot (generally room temperature, $25{ }^{\circ} \mathrm{C}$ ) the temperature of the environment does not affect the results. For example, in the assay of alkaline phosphatase, we obtained the same rate at $10,15,20$, $25,30,35$, and $40^{\circ} \mathrm{C}$ external temperature, provided 
we added the blood from a sample kept at $25{ }^{\circ} \mathrm{C}$. This represents a significant improvement.

4. The reagents used in present clinical procedures are unstable, and new solutions must be prepared daily. $o$-Toluidine and peroxidase in glucose assay, or NAD in LDH assay are examples of this. Yet when the reagents are placed in solid form on a surface, they can be kept for months with no deterioration. In our $\mathrm{ChE}$, alkaline phosphatase and LDH assays, we found we could use our pads for 90 days, using the same calibration plot everyday.

5. Many clinical methods are subject to interferences because of (a) protein absorption in the near UV-visible or (b) absorbing impurities in the reagents. By using reagents that fluoresce in the visible, and reagents in a solid form, these two interferences are eliminated.

\section{References}

[1] Guilbault, G. G., Anal. Chem. 38,527R (1966).

[2] Guilbault, G. G., Anal. Chem. 40,459R (1968).
[3] Guilbault, G. G., Anal. Chem. 42,334R (1970).

[4] Guilbault, G. G., Enzymatic Methods of Analysis, (Pergamon Press, 1970).

[5] Bergmeyer, H., Methods of Enzymatic Analysis (Verlag Chemie, Germany, 1965)

[6] Guilbault, G. G., and Zimmerman, R., Anal. Letters 3, 133 (1970).

[7] Guilbault, G. G., and Vaughn, A., Anal. Letters 3, 1 (1970).

[8] Guilbault, G. G., and Vaughn, A., Anal. Chem. 43, 721 (1971).

[9] Guilbault, G. G., and Vaughn, A., Anal. Chem. Acta 55, 107 (1971).

[10] Guilbault, G. G.. and Hieserman, J. Anal. Chem. 41, 2006 (1969).

[11] Guilbault, G. G., and Kramer, D. N., Anal. Chem. 36, 2497 (1964).

[12] Guilbault, G. G., and Zimmerman, R., Anal. Chim. Acta, 58, 75 (1972).

[13] Bergmeyer, H., Bernt, E., and Hass, B., in Methods of Enzymatic Analysis, H. Bergmeyer, Ed, (Academic Press, New York, 1963), p. 736.

[14] Guilbault, G. G., Brignac, P., and Zimmer, M., Anal. Chem. 40, 1256 (1968).

[15] Guilbault, G. G., and Tang, D., unpublished results.

(Paper 76A6-745) 